\title{
INVESTIGATING FACTORS AFFECTING ROAD FREIGHT OVERLOADING THROUGH THE INTEGRATED USE OF BLR AND CART: A CASE STUDY IN CHINA
}

\author{
Yikai $\mathrm{CHEN}^{1 *}$, Kai WANG ${ }^{2}$, Yu ZHANG ${ }^{3}$, Renjia $\mathrm{LUO}^{4}$, Shujun $\mathrm{YU}^{5}$, Qin SHI ${ }^{6 *}$, Wenting $\mathrm{HU}^{7}$ \\ 1,2, 4, 5, 6, 7 School of Automotive and Transportation Engineering, Hefei University of Technology, Hefei, China \\ ${ }^{3}$ Dept of Civil and Environmental Engineering, University of South Florida, Tampa, United States
}

Received 15 October 2018; revised 24 March 2019; accepted 29 April 2019

\begin{abstract}
Overloading of road freight vehicles accelerates road damage, creates unfair competition in the transport market, and increases safety risk. There is a dearth of research on the mining of data of highway Freight Weight (FW), and this paper therefore aims to discover factors affecting road freight overloading based on highway FW data, with a view of developing strategies to mitigate such occurrences. A comprehensive sampling survey of road freight transportation was conducted in Anhui Province (China). Vehicle Characteristics (VC), Operation Mode (OM), and transportation information from a total of 3248 trucks were collected. In order to take advantage of the strengths associated with both statistical modelling techniques and non-parametric methods, a Classification And Regression Tree (CART) technique was integrated with Binary Logistic Regression (BLR) to reveal the factors affecting road freight overloading. The classification efficacy test shows that the BLR-CART method outperformed the BLR method in term of accuracy. It is also revealed that the factors affecting overloading of freight vehicles are the Type of Transportation (ToT), Rated Load (RL), OM, FW during the investigation period, interaction between RL and FW, and interaction among RL, FW, and Average Haul Distance (AHD). Road transport authorities should pay greater attention to these factors in order to improve efficiency and effectiveness of overloading inspection.
\end{abstract}

Keywords: highway transportation, overloaded trucking, sampling survey, classification and regression tree (CART), binary logistic regression (BLR), overloading inspection.

\section{Introduction}

Road freight transport is one of the dominant modes of freight transportation of the world. As the number of heavy trucks increases progressively, more and more developing countries are preoccupied with solving the problem of overloaded trucking, due to the lack of transport infrastructure and effective enforcement of truck load regulation. According to data collected at some Weigh-InMotion (WIM) stations, in China, Indonesia and Malaysia, overloaded trucks account for $40 . . .70 \%$ of all trucks during peak months (Jihanny et al. 2018; Yassenn et al. 2011; Zhao et al. 2012), and the average overloading ratio (i.e. load of goods that exceeds the Rated Load (RL) divided by the rated vehicle load) for the overloaded trucks varies between $25 \ldots 70 \%$. For bulk goods transportation (e.g., coal, sand, ore, iron) of China, the maximum overloading ratio hits 400\% (Li et al. 2009; Wu et al. 2012).
Previous studies have demonstrated a number of fundamental issues created by overloaded trucks, including accelerated pavement wear, unfair competition, and increased risk of road crash (Deng, Yan 2018; Karim et al. 2013; Zhang et al. 2012b; Rys et al. 2016). Pais et al. (2013) found that overloading of freight vehicles results in accelerated aging of road structures such as bridges and viaducts and the substructure of roads. The maintenance costs of roads due to overloaded vehicles are at least $100 \%$ higher than those with legal loads. Similarly, Titi et al. (2018) revealed that a typical overweight truck is predicted to contribute over $1000 \%$ of the bottom-up fatigue cracking caused by a typical legal-weight truck. In addition to accelerated pavement wear, Van Loo and Henny (2005) indicated that overloading creates an illegal and unfair advantage for some operators, allowing them

\footnotetext{
${ }^{*}$ Corresponding author. E-mail: yikaichen@hfut.edu.cn

${ }^{* *}$ Corresponding author. E-mail: shiqin@hfut.edu.cn
} 
to pay lower prices per kilo of goods for the same journey. Furthermore, overloading may result in longer braking distances, decreased vehicle stability, and more frequent unsafe manoeuvres made by other vehicles, which follow the slow-moving overloaded vehicle (Brewer 2000; Jacob, Feypell-de La Beaumelle 2010), which may increase the occurrence of traffic crashes.

In order to solve the problems caused by overloading, during the last few decades, numerous weight enforcement campaigns have been conducted in many countries to prevent truck overloading. In the United States, Europe, Canada and Japan, on-board load sensors and fixed weighing stations consisting of WIM, video cameras, and static weighing equipment have been implemented to identify and continuously monitor overloaded trucks (Devlin 2008; Jacob, Van Loo 2008; Trzciński et al. 2017, 2018). For overloaded trucks identified by these detection systems, a warning is sent to the registered owners and they are subjected to pay charges with a deterrent amount of money. With regard to recidivist carriers, a probationary period is enforced (Honefanger et al. 2007). With these efforts, the enforcement campaigns successfully restricted most overloaded vehicles from entering the highways (Hamsley et al. 2007). The situation in China, however, is quite different. Before 2016, although fixed weighing stations and mobile weighing stations were used comprehensively to identify overloaded trucks, the truck was released and continued travelling to its destination if the drivers paid a fine. The regulation has, however, become much stricter since September 2016 after new legislation was published by the Ministry of Transport (China), which stipulated that, in addition to a fine up to $30000 \mathrm{CNY}$ to the owners or drivers of oversized or overloaded trucks, trucks must go to a designated fixed weighing station to discharge or transfer goods to other trucks. In addition, registered owners are recorded on a "blacklist" by the Traffic Management Department (MoT PRoC 2016).

In addition to practical measures, a limited number of studies pertaining to this area have been undertaken that focus on the analysis of the economic relationship between government, carriers, and other road freight participants, as well as suitable countermeasures for overloading. In Zhang et al. (2012a) research, a nested logit model was developed considering the hierarchical relationship between the degree of overload and the trip route for the carrier, and the trip decision behaviours of overloaded vehicles were analysed. Moreno-Quintero et al. (2013) proposed a bi-level modelling approach to represent the interaction between the vehicle loading practices of road freight transport carriers and the decisions of a road planning authority. The optimal number of inspection sites and fine level was proposed to minimize road maintenance cost. To solve the problem of overloaded trucks on intercity freight systems, Liu et al. (2017) developed a system dynamics model to represent the interactions of different agent (e.g., freight owners, infrastructure operators, government) decisions and performed a long-term evaluation of alternative modal shift policies in terms of economic effects and social and environmental effects. Torres Martínez et al. (2018) employed the Highway Development and Management 4 (HDM4) model to assess the economic benefits of enforcing axle-load regulations by applying it to the Douala-N'Djamena corridor in Cameroon. They found that every EUR invested on axle-load control generates more than 20 EUR of savings in road user costs and road maintenance and rehabilitation expenditures. In research, based on the experimental data of trucks' axle load collected by WIM system, the chaos theory has been applied to predict the ratio of trucks likely to be overloaded in order to make an appropriate time table of human resources in vehicles' axle loads control (Mahmoudabadi, Abolghasem 2013).

Despite the contributions of the previous work, identification of factors affecting road freight overloading is seriously insufficient due to the lack of reliable data of highway freight transportation. Knowing influencing factors such as characteristics of truck, route, and carrier Operation Mode (OM) would facilitate supervision at loading sites and the location of targeted inspection towards suspicious trucks on the preferred routes of overloaded truck. These, in turn, help reduce enforcement costs and promote efficiency.

Methodologies that identify influencing factors are two-folds:

- linear regression models based on statistical modelling techniques, such as binary/multivariate logit and probit models, log-linear models, etc. (Mannering, Bhat 2014; Xu et al. 2015). One limitation associated with the above traditional linear regression models is strict assumptions are required, e.g., outcomes are independent, variations among individuals are small enough to be neglected. This limitation can be alleviated by more advanced linear regression models, e.g., the hierarchical logit, nested logit, multi-level logit, mixed logit, heteroskedastic probit (Mujalli, De Oña 2013);

- nonlinear regression / non-parametric models based on data mining and machine learning (e.g. decision trees, artificial neural network, support vector machine, Bayesian networks random forest, memory based reasoning, boosting, bagging and ensemble) (Stanfill, Waltz 1986; Adla et al. 2014; Bhattacharya, Mishra 2018; Brar, Elsayed 2018; Li et al. 2014; Nesa et al. 2018; Wang et al. 2018; You et al. 2017). Linear regression models require the relationship between the dependent and explanatory variables follows a linear function. When this is not hold true, nonlinear regression models are more promising choices. Nonlinear regression models are well-known for their capability of extracting the useful hidden information from the massive archived data as well as their superior performance in classification and prediction. In spite of the effectiveness of the linear and nonlinear regression models, which were frequently used in 
previous studies, a combination of high-performance models usually result in better accuracy due to generalization (Abdel-Aty et al. 2012).

In order to mitigate the research gaps mentioned above, this paper identifies factors affecting road freight overloading based on data collected from a survey of highway FW of Anhui Province (China) in 2015. An integrated Binary Logistic Regression (BLR) - Classification And Regression Tree (CART) model (BLR-CART), which combines the advantages of both linear and nonlinear regression models, is proposed to analyse the data. First, the BLR model and the CART model were used to identify the main effects of factors affecting road freight overloading, respectively. Continuous independent variables, which were not identified by the former but were identified by the latter, were grouped according to the results of the CART model and then re-entered into the BLR model. Second, the interaction terms of factors derived from the CART model were re-entered into the BLR model. Subsequently, a classification efficacy test was used to demonstrate the advantage of the integrated BLR-CART model over the traditional BLR model. Finally, based on the final factors identified by the BLR-CART model, enforcement countermeasures for overloaded trucks were proposed in terms of policy formulation, supervision, and administration.

\section{Methods}

\subsection{Conception of BLR-CART model}

Logistic regression is a multivariate analysis method widely used for quantitative description of the relationship between dependent and independent variables (Zuo et al. 2016). BLR is applied when the dependent variables are binary. However, such method has the following caveats:

- logistic regression focuses on the main effects of independent variables. When there are more independent variables, the number of possible interaction terms increases rapidly. The inclusion of all the possible interaction terms will negatively affect the goodness-of-fit and classification efficacy of the model. Thus, in current studies, the incorporation of interaction terms depends more on experience and professional judgment. In this respect, the interaction effects between variables are usually not completely explored (Lei et al. 2015);

- when continuous independent variables and dependent variables are nonlinearly related, the significance of continuous independent variables may be erroneously predicted (Wang, Priestley 2017).

The CART model can resolve these problems effectively, as it can analyse the mechanism of a variable in subgroups in detail to clearly demonstrate the interaction effects between variables and their relationships. Furthermore, for continuous explanatory variables, the CART model can derive the optimal grouping modes with maximum information gains (Lei et al. 2015). However, the CART model cannot explain the main effects of independent variables properly, which happens to be the strong points of the logistic regression.

Therefore, this study proposed an integrated BLRCART model, which takes advantage of strengths of both BLR and CART, to identify impact factors affecting road freight overloading. First, significance tests were performed for all independent variables, and those not showing statistical significance were eliminated. Second, the BLR and CART models were applied respectively to identify impact factors to road freight overloading. For continuous independent variables identified by the CART model but not by the BLR model, grouping was performed according to the division results of the CART model and then were included in the BLR model. Meanwhile, the interaction terms acquired by the CART model were also included in the BLR model. This refined BLR model is estimated with the survey data explained earlier. The details of the BLR-CART model are given in the following subsections.

\subsection{Significance tests of independent variables}

Before the inclusion of independent variables into the BLR and CART models, both $t$-test and chi-square test were applied, respectively, to continuous variables and categorical variables in Table 1 (Gilbert, Prion 2016; Kim et al. 2015; Menard 2001). Independent variables showing no statistical significance $(p<0.05)$ were eliminated from the dataset.

\subsection{BLR analysis}

First, BLR regression analysis was conducted based on the independent variables that passed the significance test to recognize the main effects of the impact factors to road freight overloading. The possibility of overloading is expressed as follows (Ramos et al. 2017):

$$
p(y)=\frac{e^{\beta_{0}+\beta_{1} \cdot x_{1}+\ldots+\beta_{m} \cdot x_{m}}}{1+e^{\beta_{0}+\beta_{1} \cdot x_{1}+\ldots+\beta_{m} \cdot x_{m}}},
$$

where: $x_{1}, x_{2}, \ldots, x_{m}$ are independent variables; $\beta_{0}$ is constant quantity; $\beta_{1}, \beta_{2}, \ldots, \beta_{m}$ are regression coefficients; $y$ is a binary dependent variable ( $y=1$ indicates overload, $y=0$ indicates not overload).

\subsection{CART analysis}

After the identification of the main effects of the impact factors using BLR regression analysis, CART analysis was applied to determine other main effects and the interaction terms (Bremner, Taplin 2015; Nishida et al. 2005). In the CART analysis, the minimum Gini change value was set at 0.0001 , the missing value of the tree during its growth was excluded, and the decision tree was trimmed by the "cost-complexity pruning" method (Hu, Steingrimsson 2018). The complexity parameter was set at 1 , and the samples were verified by the splitting method; $80 \%$ of the samples were randomly drawn to form the training set and $20 \%$ to form the test set. 
For continuous independent variables identified by the CART model but not by the BLR model, grouping was performed according to the division results of the CART model, and then the continuous independent variables became categorical independent variables. The categorical independent variables and interaction terms that passed the goodness-of-fit likelihood-ratio test in the CART model were re-included into the BLR model to yield the final analytical results.

\section{Data collection}

Truck samples were taken from the Anhui Operating Trucks Database maintained by the Road Transport Administration of Anhui Province (RTAAP). The database includes the information of all the trucks registered in the 16 cities of Anhui Province. Truck types in the database included Container Car (CC), Van (V), Tank Car (TC), tractor-semi-trailer, Ripping Fence Truck (RFT), and others. The sampling process is as follows: First, the sample size of each type of truck accounts for $0.5 \%$ of the total number of the type of truck registered in Anhui Province. Second, the sampled size of each type of truck is divided to each city according to the respective proportion of the type of truck of the city in Anhui Province. Finally, trucks are sampled randomly in each city. The sample sizes of the cities are illustrated in Figure 1.

In total, 3440 sample trucks were drawn for the survey. During the survey, questionnaires were forwarded to truck drivers or freight corporation managers by officers of RTAAP to ask questions about vehicular characteristics, $\mathrm{OM}$ and Transport Information (TI). Each driver was offered a reward after completing the survey, and their answers were confidential to truck owners and local road freight authorities. The survey was launched on 1 June 2015, and lasted 10 days. Overall, 3419 questionnaires were gathered, of which 3248 presented complete and effective data. The distribution of the questionnaires across cities is illustrated in Figure 1, and the summary of the data is tabulated in Table 1 .

As shown in Table 1. With respect to Vehicle Type (VT), Other Cargo Vehicles (OCV) include low-speed agricultural vehicle and wheeled tractor. FW is the total FW within the 10 days of the survey. Average Haul Distance (AHD) is the average distance of a trip.

To identify key factors to road freight overloading, dependent and independent variables need to be defined first. Dependent variables relate to whether a truck has previously had an overloaded trip. Thus, a binary dependent variable was used and defined as $1=$ overload, $0=$ not overload. Independent variables consisted of Vehicle Characteristics, OMs, and TI. VC included VT, VL, RL, Number of Axles (NA), Engine Power (EP) and Engine Displacement (ED). TI included Type of Goods (TG), Type of Transportation (ToT), Travel Mileage (TM), Fuel Consumption (FC), Freight Mileage (FM), FW and AHD. The definitions and descriptions of the 14 independent variables are shown in Table 2.

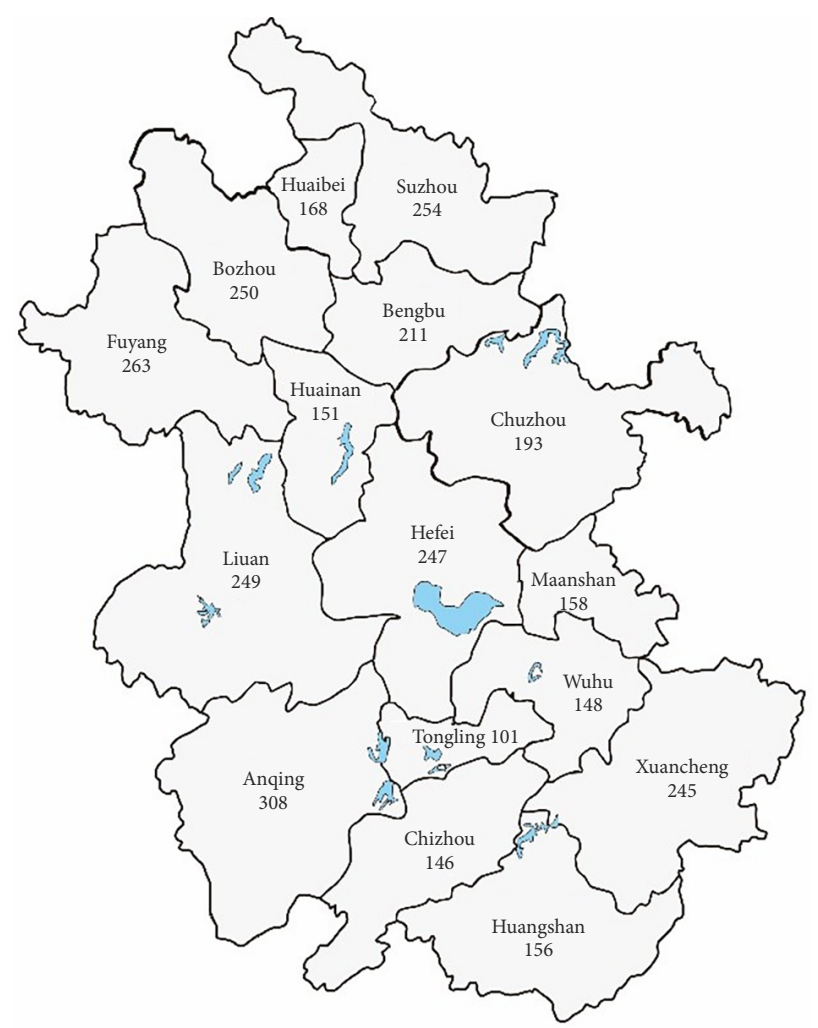

Figure 1. Sample trucks of each city in Anhui Province of China

Table 1. Summary of the survey data

\begin{tabular}{|l|c|c|c|}
\hline \multicolumn{1}{|c|}{ VT } & $\begin{array}{c}\text { Number } \\
\text { of vehicles }\end{array}$ & $\begin{array}{c}\text { FW } \\
{[1000 \mathrm{t}]}\end{array}$ & $\begin{array}{c}\text { AHD } \\
{[\mathrm{km}]}\end{array}$ \\
\hline Tired Tractor (TT) & 49 & 48.9 & 59.42 \\
\hline CC & 26 & 32.9 & 209.86 \\
\hline V & 941 & 6355.4 & 83.65 \\
\hline TC & 103 & 4433.5 & 40.98 \\
\hline Semitrailer (S) & 436 & 14678.1 & 443.32 \\
\hline RFT & 1555 & 37225.9 & 140.24 \\
\hline OCV & 138 & 1622.0 & 73.45 \\
\hline Total & 3248 & 64396.7 & - \\
\hline
\end{tabular}

Some variables shown in Table 2 need further explanation. With respect to OM, Cooperation Operation (CO) is an $\mathrm{OM}$ in which vehicles are attributed to the corporation and dispatched and managed by the corporation; incomes and costs are circulated by the corporation as a whole. Whereas Non-Cooperation Operation (NCO) refers to operating certificates in the name of the transport company, the corporation takes certain management responsibilities for collecting management fees, but is not responsible for the specific operation and transportation activities of the vehicles. Individual Operation (IO) is a kind of OM for operating certificates in the name of individuals, and the individuals have responsibility for the operation. Regarding TI, TG is the TG with the maximum weight during the survey period. TM, FC, FM and FW mean the total amount of the respective variable during the survey period. 
Table 2. Classification and description of independent variables

\begin{tabular}{|c|c|c|}
\hline Item & Name of independent variable & Definition and assignment \\
\hline \multirow{12}{*}{ Vehicle Characteristics (VC) } & \multirow{7}{*}{ Vehicle Type (VT) } & $0=$ Other Cargo Vehicles $(\mathrm{OCV})$ \\
\hline & & $1=$ Tired Tractor $(\mathrm{TT})$ \\
\hline & & $2=$ Container Car $(\mathrm{CC})$ \\
\hline & & $3=\operatorname{Van}(\mathrm{V})$ \\
\hline & & $4=$ Tank Car (TC) \\
\hline & & $5=$ Semitrailer $(S)$ \\
\hline & & 6 = Ripping Fence Truck (RFT) \\
\hline & Vehicle Length (VL) & continuous variable \\
\hline & Rated Load (RL) & continuous variable \\
\hline & Number of Axles (NA) & continuous variable \\
\hline & Engine Power (EP) & continuous variable \\
\hline & Engine Displacement (ED) & continuous variables \\
\hline \multirow{3}{*}{ Operation Mode (OM) } & \multirow{3}{*}{-} & $0=$ Cooperation Operation $(\mathrm{CO})$ \\
\hline & & $1=$ Non-Cooperation Operation $(\mathrm{NCO})$ \\
\hline & & 2 = Individual Operation $(\mathrm{IO})$ \\
\hline \multirow{15}{*}{ Transport Information (TI) } & \multirow{5}{*}{ Type of Goods (TG) } & $0=$ Special Goods $(\mathrm{SG})$ \\
\hline & & $1=$ Radioactive Objects (RO) \\
\hline & & $2=$ Large Objects $(\mathrm{LO})$ \\
\hline & & $3=$ Non-radioactive Hazardous Goods (NHG) \\
\hline & & 4 = General Goods (GG) \\
\hline & \multirow{5}{*}{ Type of Transportation (ToT) } & $0=$ Concrete Transport $(\mathrm{CT})$ \\
\hline & & $1=$ House-moving Service (HS) \\
\hline & & 2 = Muck and Gravel Transportation (MGT) \\
\hline & & $3=$ City Delivery $(\mathrm{CD})$ \\
\hline & & $4=$ Trunk-Road Transportation (TRT) \\
\hline & Travel Mileage (TM) & continuous variable \\
\hline & Fuel Consumption (FC) & continuous variable \\
\hline & Freight Mileage (FM) & continuous variable \\
\hline & Freight Weight $(\mathrm{FW})$ & continuous variable \\
\hline & Average Haul Distance (AHD) & continuous variable \\
\hline
\end{tabular}

\section{Results}

\subsection{Results of BLR-CART model}

After the significance test, 11 statistically significant variables $(p<0.05)$ were obtained: TG, VL, ToT, VT, OM, NA, $\mathrm{ED}, \mathrm{FC}, \mathrm{FM}, \mathrm{FW}$ and AHD.

These variables were fitted by BLR, and the multicollinearity among the independent variables was eliminated through stepwise regression. The results of BLR model are shown in Table 3. The main effects of factors of overloading are ToT, VL, OM, FW and AHD.

The 11 statistically significant independent variables also were entered into the CART model; the results are shown in Figure 2. Each interior node corresponds to one of the input variables; each leaf represents a value of the target variable (not overload, overload) given the values of the input variables represented by the path from the root to the leaf. As shown, the first-order interactions ex- ist between $\mathrm{FW}$ and $\mathrm{RL}$, and the second-order interaction exists among FW, RL and AHD, as well as among FW, $\mathrm{RL}$, and $\mathrm{OM}$.

With respect to the main effects of the impact factors, $\mathrm{RL}$, which is a continuous variable, appeared in the CART model but not the BLR model. Therefore, it was necessary to group the RL. According to the results of the CART model, $\mathrm{RL}<5.958 \mathrm{t}, 5.958 \leq \mathrm{RL} \leq 16.005 \mathrm{t}$ and $\mathrm{RL}>16.005 \mathrm{t}$ were defined as small tonnage, medium tonnage, and large tonnage, respectively. After the grouped RL was included in the BLR model, the deviance in the likelihood-ratio test decreased and the variable became statistically significant $(p<0.05)$, indicating that the inclusion of the grouped RL improved the goodness-of-fit of the model. Similarly, all the interaction terms also passed the likelihood-ratio tests.

Subsequently, the discrete RL and the interaction terms were re-included in the BLR model. After the stepwise regression, the final key factors (main effects and in- 
teraction terms) impacting road freight overloading are shown in Table 4.

It should be noted that accurate explanations of the effects of interaction terms on overloading could be difficult based on the results of Table 4. For example, with regard to the interaction between RL and FW, only the product

Table 3. Analysis results of traditional BLR model

\begin{tabular}{|l|c|c|c|c|c|c|}
\hline Variable & $\beta$ & S.E. & Wald & df & Sig. & $\exp (\beta)$ \\
\hline ToT & - & - & 19.822 & 4 & 0.001 & - \\
\hline HS & 1.276 & 0.700 & 3.326 & 1 & 0.068 & 3.583 \\
\hline MGT & 0.896 & 0.246 & 13.314 & 1 & 0.000 & 2.449 \\
\hline CD & 0.894 & 0.212 & 17.852 & 1 & 0.000 & 2.446 \\
\hline TRT & 0.720 & 0.215 & 11.180 & 1 & 0.001 & 2.055 \\
\hline VL & -0.139 & 0.023 & 104.975 & 1 & 0.000 & 0.867 \\
\hline OM & - & - & 44.303 & 2 & 0.000 & - \\
\hline CO & -0.122 & 0.142 & 0.735 & 1 & 0.391 & 0.885 \\
\hline IO & 0.663 & 0.162 & 16.699 & 1 & 0.000 & 1.940 \\
\hline FW & 0.008 & 0.001 & 95.731 & 1 & 0.000 & 1.008 \\
\hline AHD & 0.001 & 0.000 & 9.991 & 1 & 0.002 & 1.001 \\
\hline $\begin{array}{l}\text { Constant } \\
\text { quantity }\end{array}$ & 0.287 & 0.404 & 0.506 & 1 & 0.477 & 1.333 \\
\hline
\end{tabular}

Notes: $\beta$ - regression coefficient; S.E. - standard error; Wald Wald chi-square; df - degree of freedom; Sig. - significance. of medium tonnage and FW is significant. As the product increases by 1 , the probability of overloading decreases by $0.2 \%$, so the influence is too small to be taken into account. Similar findings can be discovered with other interaction terms. However, the CART model can address this problem well. The interaction rules of Table 5 can be obtained from Figure 2. Inspections should be carried out towards vehicles with the described characteristics shown in Table 5, thus improving the efficiency of overloading management.

\subsection{Comparison between BLR-CART model and traditional BLR model}

The accuracy of the BLR-CART model was compared with that of the traditional BLR model with the Area Under Curve (AUC) of the Receiver Operating Characteristic (ROC). The larger the AUC, the higher the accuracy of the model (Nandi, Shakoor 2010). As shown in Figure 3 and Table 6, the AUC of the traditional BLR model is 0.736, and the AUC of the BLR-CART model is 0.786, higher than that of the traditional BLR model. The $Z$-value between the two models is 3.3634 , and the calibration level is $\alpha=0.05$. With reference to the $U$-bound table (Iyama et al. 2017), the difference between the two models is statistically significant. Therefore, the classification efficacy of the BLR-CART model is better than that of the traditional BLR model.

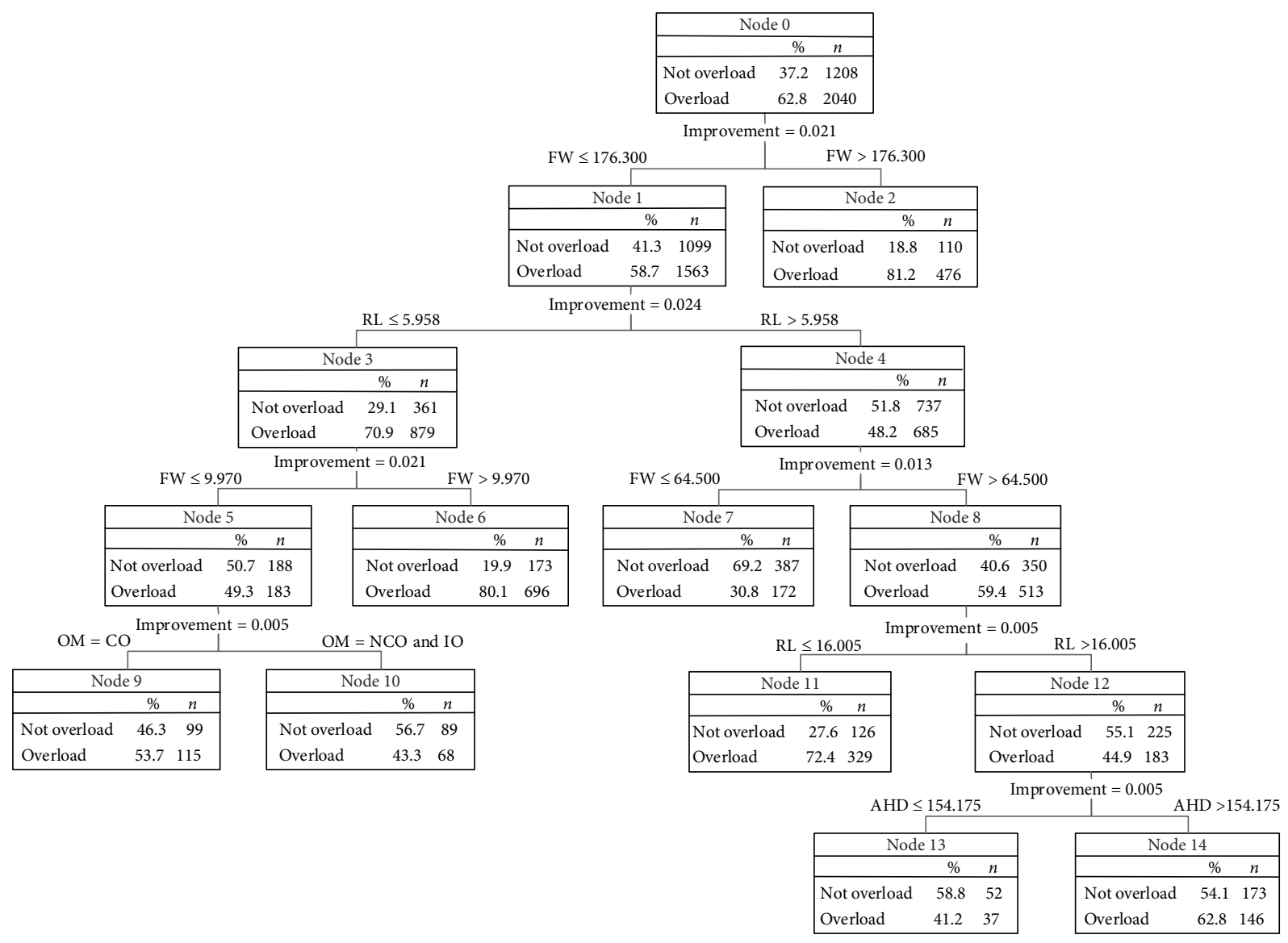

Figure 2. Results of CART model 
Table 4. Analysis results of BLR-CART model

\begin{tabular}{|c|c|c|c|c|c|c|}
\hline Variable & $\beta$ & S.E. & Wald & $\mathrm{df}$ & Sig. & $\exp (\beta)$ \\
\hline ToT & - & - & 20.403 & 4 & 0.000 & - \\
\hline HS & 1.369 & 0.686 & 3.977 & 1 & 0.046 & 3.931 \\
\hline MGT & 0.839 & 0.210 & 16.014 & 1 & 0.000 & 2.315 \\
\hline $\mathrm{CD}$ & 0.663 & 0.177 & 13.943 & 1 & 0.000 & 1.940 \\
\hline TRT & 0.528 & 0.180 & 8.610 & 1 & 0.003 & 1.696 \\
\hline RL & - & - & 6.567 & 2 & 0.037 & - \\
\hline $\begin{array}{l}\text { Medium } \\
\text { tonnage }\end{array}$ & -0.228 & 0.182 & 1.575 & 1 & 0.209 & 0.796 \\
\hline Large tonnage & -0.573 & 0.225 & 6.508 & 1 & 0.011 & 0.564 \\
\hline $\mathrm{OM}$ & - & - & 46.479 & 2 & 0.000 & - \\
\hline $\mathrm{CO}$ & -0.090 & 0.111 & 0.662 & 1 & 0.416 & 0.914 \\
\hline IO & 0.655 & 0.135 & 23.545 & 1 & 0.000 & 1.925 \\
\hline FW & 0.048 & 0.007 & 46.299 & 1 & 0.000 & 1.049 \\
\hline $\mathrm{RL} \cdot \mathrm{FW}$ & - & - & 39.324 & 2 & 0.000 & - \\
\hline $\begin{array}{l}\text { Medium } \\
\text { tonnage } \cdot \mathrm{FW}\end{array}$ & -0.002 & 0.000 & 17.275 & 1 & 0.000 & 0.998 \\
\hline $\begin{array}{l}\text { Large } \\
\text { tonnage } \cdot \mathrm{FW}\end{array}$ & 0.000 & 0.000 & 3.158 & 1 & 0.076 & 1.000 \\
\hline $\mathrm{RL} \cdot \mathrm{FW} \cdot \mathrm{AHD}$ & - & - & 29.399 & 2 & 0.000 & - \\
\hline $\begin{array}{l}\text { Medium } \\
\text { tonnage } \cdot \text { AHD }\end{array}$ & 0.000 & 0.000 & 1.617 & 1 & 0.204 & 1.000 \\
\hline $\begin{array}{l}\text { Large } \\
\text { tonnage } \cdot \text { AHD }\end{array}$ & 0.000 & 0.000 & 5.606 & 1 & 0.018 & 1.000 \\
\hline $\begin{array}{l}\text { Constant } \\
\text { quantity }\end{array}$ & 0.287 & 0.404 & 0.506 & 1 & 0.477 & 1.333 \\
\hline
\end{tabular}

Notes: $\beta$ - regression coefficient; S.E. - standard error; Wald Wald chi-square; $\mathrm{df}$ - degree of freedom; Sig. - significance.

Table 5. Interaction rules

\begin{tabular}{|c|c|c|c|c|}
\hline Rule & $\begin{array}{c}\text { RL } \\
{[\mathrm{t}]}\end{array}$ & $\begin{array}{c}\mathrm{FW} \\
{[\mathrm{t}]}\end{array}$ & $\begin{array}{c}\text { AHD } \\
{[\mathrm{km}]}\end{array}$ & $\begin{array}{c}\text { Overloading } \\
\text { probability } \\
{[\%]}\end{array}$ \\
\hline 1 & $(0,5.958]$ & $(9.97,176.3]$ & - & 80.1 \\
\hline 2 & $(0,5.958]$ & $(64.5,176.3]$ & - & 59.4 \\
\hline 3 & $(5.958,16.005]$ & $(64.5,176.3]$ & - & 72.4 \\
\hline 4 & $(0,5.958]$ & {$[0,176.3]$} & - & 70.9 \\
\hline 5 & $>16.005$ & $(64.5,176.3]$ & $>154.175$ & 62.8 \\
\hline
\end{tabular}

Table 6. ROC comparison between BLR-CART model the traditional BLR model

\begin{tabular}{|c|c|c|c|c|c|}
\hline \multirow[b]{2}{*}{ Model } & \multirow[b]{2}{*}{ Area } & \multirow[b]{2}{*}{ S.E. } & \multirow[b]{2}{*}{ Sig. } & \multicolumn{2}{|c|}{ Progressive $95 \%$ range } \\
\hline & & & & $\begin{array}{c}\text { lower } \\
\text { limit }\end{array}$ & $\begin{array}{l}\text { upper } \\
\text { limit }\end{array}$ \\
\hline $\begin{array}{l}\text { Traditional } \\
\text { BLR }\end{array}$ & 0.736 & 0.011 & 0.000 & 0.715 & 0.757 \\
\hline BLR-CART & 0.786 & 0.010 & 0.000 & 0.767 & 0.805 \\
\hline
\end{tabular}

Notes: S.E. - standard error; Sig. - significance.

\section{Discussion}

Based on Table 4, the influences of the factors on overloading are analysed, and corresponding countermeasures are proposed in the following.

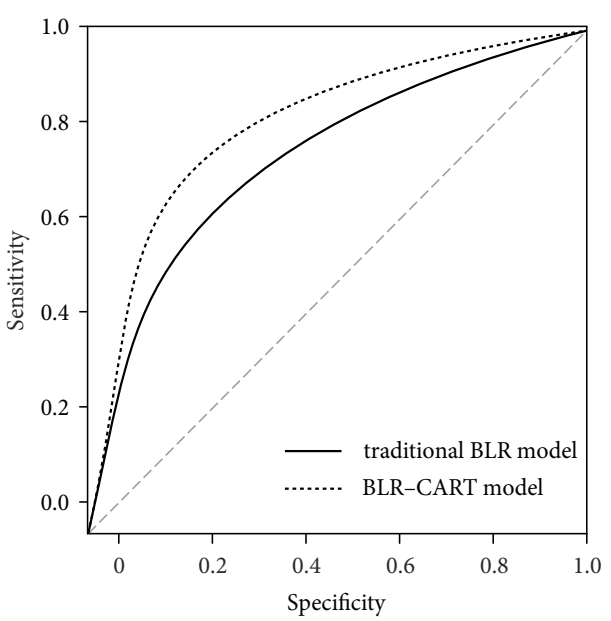

Figure 3. ROC curves of BLR-CART model and traditional BLR model

Regarding effects of ToT on road freight overloading, as indicated in Table 1, CT is a reference type for the categorical variable - ToT. According to the high-to-low order of the overloading probability shown in Table 3, ToT are HS, MGT, CD, TRT and other.

HS transportation has the highest overloading probability, which is 3.931 times of the "other" type. The main reason may relate to the fact that the house-moving industry has rapidly developed in recent years and has a relatively low market entrance threshold. There are no regulations available for overseeing this booming industry, so it is out of order and lacks supervision. Under such circumstances, house-moving companies usually carry excess freight to save cost. In addition, MGT, which usually occurs at night, is also highly overloaded. This relates to the loose nighttime management of the urban traffic management departments. The next two types are $\mathrm{CD}$ and TRT. CD vehicles usually take local streets or arterials, and the overloading investigation on these roads is relatively loose and less frequent. However, TRT takes mainly toll highways that are under strict supervision (Hang et al. 2005). To address these issues, the government should set up relevant regulations and industry standards for HS companies, and road freight authorities should strengthen nighttime inspections for gravel overloading, focusing on roads around construction sites, factories, and mines, as well as implementing an accountability system for construction sites. In addition, since $\mathrm{CD}$ vehicles have many alternative routes, it would be more effective to implement unscheduled inspections at warehouses and supermarkets than strengthening inspections on roads.

With regard to effects of RL on road freight overloading, according to Table 4, vehicles with smaller RL have a high overloading probability, which is different from the conclusion of Moreno-Quintero et al. (2013), showing that vehicles with greater load capacity are more likely to be overloaded. However, in accordance with the findings from the previous section, HS and city deliveries, which are overload-prone transportation types, usually prefer the use of vehicles with a smaller RL. 
Since large vehicles are the main causes of pavement damage, larger vehicles have a lower overloading probability than vehicles with smaller RL, demonstrating the effectiveness of overloading enforcement in China, especially the widespread use of the toll-by-weight method. In recent years, many highways and bridges in China have been constructed and financed by local governments and the private sector, with investments paid off by collecting user tolls. Initially, most tolls in China were collected based on vehicle class and verified load capacity. However, past experience in China showed that this toll fee structure does not charge vehicles based on their actual damage to the roads. In particular, heavily-overloaded trucks pay less than what their use of the roadway system is worth (Hang et al. 2013). The toll-by-weight method, which charges truck drivers according to loaded weight, can guarantee that trucks are charged more fairly and maximize the return from highway investments. Thus, in October 2005, the Ministry of Transport of People's Republic of China issued a formal document to encourage more provinces and municipalities to switch to the toll-byweight toll method. Currently, more than $90 \%$ of highways in China have implemented this method.

In the toll-by-weight method, the excess charge on the overloaded weight is calculated by the product of the overlimit penalty rate (CNY/tkm), overloaded weight and TM. Thus, this phenomenon of our finding may be explained that with the same overloading rate, the penalty on smaller vehicles is much less than that of larger vehicles, owing to lower overloaded weight. The cost of violating the law is not high enough to raise the attention of owners of small RL vehicles, so they are more willing to take the risk of overloading to gain additional profits. Another reasonable explanation is that small trucks (such as agricultural trucks) are more easily refitted than large trucks.

The countermeasures are two-folds:

- the toll-by-weight method should be further spread and improved, paying particular attention to the enhancement of the over-limit penalty rate on vehicles with small load capacity;

- traffic police departments should implement new countermeasures towards vehicles that are converted privately, such as refusing the MOT test, conducting mandatory dismantling, or seizure (Pillay, Bosman 2001).

Regarding OM, enterprise incorporated management is taken as a reference. The overloading probability of vehicles from unincorporated enterprises is 0.914 time that of incorporated enterprises. The two are relatively close; however, the overloading probability of IO is close to twice that of corporate operation (1.925). As transport corporations have extensive supervision of their vehicles, their overloading probability is low, whereas vehicles of IO corporations can be seriously overloaded due to lack of effective and timely management and excessive pursuit of economic profits.

The reason for non-standard management of IO is complicated. In the early 1980s, the Chinese government began to open the road transport market. Since the safety of passenger transportation has a stronger social impact, the threshold of passenger transportation was relatively high, and a considerable number of vehicles and registered funds on the corresponding scale were stipulated to enter the market. The price of the operation also was carried out by the government guidance price. However, the threshold for the freight transportation market was very low to encourage its rapid development, and the situation did not change during the past three decades. The result is that among 13.7 million commercial freight vehicles in China (MoT PRoC 2018), more than $90 \%$ are operated individually. In this OM, each truck owner works separately, and his/her transport scale is very small. Because of the difficulties of effective and timely supervision by the road transportation authority, proper management of personnel, vehicle maintenance, and operation cannot be guaranteed. Therefore, overloading becomes a common phenomenon.

In the long run, it is suggested that a strict system of access to the freight transportation market be established to promote the transformation of IOs into enterprise corporations. In the near future, as individuals want to take chances and pursue profits blindly, an incentive system is suggested to give cash rewards for vehicles that have not been overloaded for a long time, reducing the occurrence of overloading. In addition, it is recommended to implement a scoring system for overloaded owners or drivers; for owners or drivers of trucks that often are overloaded or have heavy overloading, their score will be low. Once it is lower than the assigned threshold, their driving licenses are revoked, which has proved to be an effective measure in other developing countries (Torres Martínez et al. 2018).

With respect to FW, it is the sum of the mass of goods for every vehicle within the survey period (10 days). The larger FW is, the higher the overloading probability. Road damage increases as the FW of a vehicle climbs. In addition, the damage caused by overloaded trucks is not necessarily gradual. After reaching certain weight thresholds, overloaded trucks can cause immediate and disastrous damage to highways. Thus, particular attention should be given to high-severity overloading. Enforcement in China has some strengths in this respect. The toll fee structure based on toll-by-weight includes a basic rate and an overlimit penalty rate. To encourage drivers to not overload their vehicle, the basic rate is usually reduced by a certain amount (also called incentive rate) as the gross truck weight increases. To deter high-severity overloading, the over-limit penalty rate often is set to be much higher than the basic rate and increases with the overloading rate.

There also are weaknesses related to overloading enforcement in China. Toll stations are managed by highway operating agencies, whereas weight enforcement is conducted by highway administrations and traffic police departments at fixed weighing stations and mobile weighing stations on toll roads and non-toll roads; these two types of activities occur dependently. In addition, the jurisdic- 
tion of these stations belongs to each province. Thus, for long-distance haul freight transport (especially trans-provincial transportation), overloaded trucks may be charged many times for overloading, which often triggers conflicts between carriers and fee collectors (APCD 2006). Recent legislation published by the Ministry of Transport of People's Republic of China in 2016 stipulates that oversized (also overloaded) trucks must go to a designated fixed weighing station to discharge or transfer goods to other trucks. In theory, multiple charges on overloaded weight can be avoided in this way (MoT PRoC 2016). However, the high costs of the parking facilities, unloading areas, and alternative trucks may hinder the feasibility of enforcement of this legislation, especially for mobile weighing stations. An alternative method suggested by the authors is to develop a nationwide overloading Management Information System (MIS), which is integrated with Global Positioning System (GPS) and Radio-Frequency IDentification (RFID) techniques (McDonnell et al. 2008); once a vehicle is fined during one trip, the information is uploaded by fee collectors and stored in the MIS through wireless communication devices (e.g., cellphone, portable computer). When the same vehicle approaches the next static or mobile weighing station, RFID reader equipped in the station communicates with the RFID tag attached to the windshield of vehicle and identifies the vehicle. GPS tracking information obtained from on-vehicle systems is uploaded to the MIS to determine whether the vehicle deviated from the corridor, made specific stops to reload the vehicle. If not, the vehicle will not be fined again. Besides avoiding repeated fines, the time savings enjoyed by transporters due to a reduction in the number of weighing of vehicles combined with reduced vehicle operational costs due to fewer stops, would also provide the required incentive for participation in a voluntary overload control scheme, according to experiences of other countries (Hoffman, De Coning 2014).

In addition to the recommendations above, for corporations with large FW, it is suggested to intensify inspections around their loading sites and impose a joint punishment system, on overloaded vehicle owners, transport corporations, and goods owners (Zhou 2014). In addition, the rated power of the vehicle engines should be limited, not only to limit its loading capability but to control overloading (Li et al. 2009).

\section{Conclusions}

Since there is a dearth of research on the mining of data of highway FW, this paper aims to discover factors affecting road freight overloading based on highway FW data, with a view of developing strategies to mitigate such occurrences. Vehicular characteristics, OM, and transportation information of 3248 vehicles were sampled from the Anhui Operating Trucks Database in 2015. An integrated BLR-CART model, which combined the advantages of both linear and nonlinear regression models, was proposed to identify factors affecting road freight overload- ing. The results have shown that the BLR-CART model has better classification efficacy than the traditional BLR model.

Obtained from the BLR-CART model, the factors affecting overloading of freight vehicles include ToT, RL, $\mathrm{OM}, \mathrm{FW}$ during the investigation period, interaction between RL and FW, and interaction among RL, FW and AHD. Aiming at improving efficiency and effectiveness of overloading inspection, countermeasures were proposed in terms of market regulation, overloading inspection, punishment strategies, and policy-making. The research results have significant practical importance for different departments working collaboratively to manage transport companies and formulate overloading regulatory policies, particularly in the context of China and other developing countries.

Due to limited information in the survey, this paper does not consider the effects of the characteristics of vehicle owners and drivers, transportation time, or location/ type of road on road freight overloading. Also, the severities of overloading are not classified and considered in the model. The information provided here is useful in scheduling enforcement actions. Such limitations may be addressed in follow-up studies through the integrated use of survey results and data collected from WIM devices and static weighing equipment. With respect to the methods, the integrated use of random-parameter BLR and CART can be considered in the future. The random-parameter BLR better represents the unobserved heterogeneity in the data, compared with the BLR.

\section{Acknowledgements}

Colleagues of the project "A Special Survey of Highway Transportation in Anhui Province of China in 2015" sponsored by the Road Transport Administration of Anhui Province (RTAAP) are greatly appreciated for their assistance of collecting data.

\section{Funding}

This work was supported by the National Natural Science Foundation of China under Grant No 71871078 and the Fundamental Research Funds for the Central Universities under Grant No JZ2017HGTB0212.

\section{Author contributions}

Yikai Chen conceived the study and wrote the first draft of the paper.

Kai Wang and Qin Shi were responsible for the data collection and analysis.

Yu Zhang and Wenting Hu revised the paper.

Renjia Luo and Shujun Yu plot the figures.

\section{Disclosure statement}

The authors declare that there are no conflicts of interest. 


\section{References}

Abdel-Aty, M.; Ahmed, M.; Yu, R.; Qi, S. 2012. Developing an Active Traffic Management System for I-70 in Colorado. Final Report No CDOT-2012-9. Colorado Department of Transportation, Denver, CO, US. 193 p. Available from Internet: https://www.codot.gov/programs/research/pdfs/2012/atm.pdf

Adla, A.; Frendi, M.; Benmessaoud, N. 2014. A group memorybased framework for enterprise decision support, Frontiers in Artificial Intelligence and Applications 261: 177-187.

https://doi.org/10.3233/978-1-61499-399-5-177

APCD. 2006. Vehicle Overloading Study in Anhui Province P.R. China: Final Report. Anhui Provincial Communications Department (APCD), China. (in Chinese).

Bhattacharya, S.; Mishra, S. 2018. Applications of machine learning for facies and fracture prediction using Bayesian network theory and random forest: case studies from the Appalachian basin, USA, Journal of Petroleum Science and Engineering 170: 1005-1017. https://doi.org/10.1016/j.petrol.2018.06.075

Brar, L. S.; Elsayed, K. 2018. Analysis and optimization of cyclone separators with eccentric vortex finders using large eddy simulation and artificial neural network, Separation and Purification Technology 207: 269-283.

https://doi.org/10.1016/j.seppur.2018.06.013

Bremner, A. P.; Taplin, R. H. 2015. Theory \& methods: modified classification and regression tree splitting criteria for data with interactions, Australian \& New Zealand Journal of Statistics 44(2): 169-176. https://doi.org/10.1111/1467-842X.00219

Brewer, A. M. 2000. Road rage: what, who, when, where and how?, Transport Reviews 20(1): 49-64. https://doi.org/10.1080/014416400295338

Deng, L.; Yan, W. 2018. Vehicle weight limits and overload permit checking considering the cumulative fatigue damage of bridges, Journal of Bridge Engineering 23(7): 04018045. https://doi.org/10.1061/(ASCE)BE.1943-5592.0001267

Devlin, G. 2008. Applications and development of real-time GPS tracking systems and on-board load sensor technology for wood transport in Ireland, in COFORD Technical Workshop: Developing Cost-Effective Systems for Wood Procurement, Harvesting and Transport, 22 February 2008, Dublin, Ireland.

Gilbert, G. E.; Prion, S. 2016. Making sense of methods and measurement: the chi-square test, Clinical Simulation in Nursing 12(5): 145-146. https://doi.org/10.1016/j.ecns.2015.12.013

Hamsley, A. K.; Greene, W. D.; Siry, J. P.; Mendell, B. C. 2007. Improving timber trucking performance by reducing variability of log truck weights, Southern Journal of Applied Forestry 31(1): 12-16. https://doi.org/10.1093/sjaf/31.1.12

Hang, W.; Li, X.-H.; Ju, P.; He, J. 2005. Site survey and analysis of highway trucks overloading status quo in Anhui, Journal of the Eastern Asia Society for Transportation Studies 6: 17901803. https://doi.org/10.11175/easts.6.1790

Hang, W.; Xie, Y.; He, J. 2013. Practices of using weigh-in-motion technology for truck weight regulation in China, Transport Policy 30: 143-152.

https://doi.org/10.1016/j.tranpol.2013.09.013

Hoffman, A. J.; De Coning, A. 2014. An intelligent freight corridor overload control system, in 17th International IEEE Conference on Intelligent Transportation Systems (ITSC), 8-11 October 2014, Qingdao, China, 1732-1739. https://doi.org/10.1109/ITSC.2014.6957943

Honefanger, J.; Strawhorn, J.; Athey, R.; Carson, J.; Conner, G.; Jones, D.; Kearney, T.; Nicholas, J.; Thurber, P.; Woolley, R. 2007. Commercial Motor Vehicle Size and Weight Enforcement in Europe. Report No FHWA-PL-07-002. Federal Highway Administration (FHWA), US Department of Transportation,
Washington, DC, US. 104 p. Available from Internet: https://international.fhwa.dot.gov/pubs/pl07002

$\mathrm{Hu}, \mathrm{C}$; S Steingrimsson, J. A. 2018. Personalized risk prediction in clinical oncology research: applications and practical issues using survival trees and random forests, Journal of Biopharmaceutical Statistics 28(2): 333-349.

https://doi.org/10.1080/10543406.2017.1377730

Iyama, Y.; Nakaura, T.; Katahira, K.; Iyama, A.; Nagayama, Y.; Oda, S.; Utsunomiya, D.; Yamashita, Y. 2017. Development and validation of a logistic regression model to distinguish transition zone cancers from benign prostatic hyperplasia on multi-parametric prostate MRI, European Radiology 27(9): 3600-3608. https://doi.org/10.1007/s00330-017-4775-2

Jacob, B.; Feypell-de La Beaumelle, V. 2010. Improving truck safety: potential of weigh-in-motion technology, IATSS Research 34(1): 9-15. https://doi.org/10.1016/j.iatssr.2010.06.003

Jacob, B.; Van Loo, H. 2008. Weigh-in-motion for enforcement in Europe, in International Conference on Heavy Vehicles HVParis 2008: Weigh-In-Motion (ICWIM 5), 19-22 May 2008, Paris, France, 25-38. https://doi.org/10.1002/9781118623305.ch1

Jihanny, J.; Subagio, B. S.; Hariyadi, E. S. 2018. The analysis of overloaded trucks in Indonesia based on weigh in motion data (east of Sumatera national road case study), MATEC Web of Conferences 147: 02006.

https://doi.org/10.1051/matecconf/201814702006

Karim, M. R.; Abdullah, A. S.; Yamanaka, H.; Abdullah, A. Sh.; Ramli, R. 2013. Degree of vehicle overloading and its implication on road safety in developing countries, Civil and Environmental Research 3(12): 20-31.

Kim, J.-T.; Heo, S.-H.; Lee, J. S.; Choi, M.-J.; Choi, K.-H.; Nam, T.-S.; Lee, S.-H.; Park, M.-S.; Kim, B. C.; Kim, M.-K.; Cho, K.-H. 2015. Aspirin resistance in the acute stages of acute ischemic stroke is associated with the development of new ischemic lesions, PLoS ONE 10(4): e0120743.

https://doi.org/10.1371/journal.pone.0120743

Lei, Y.; Nollen, N.; Ahluwahlia, J.; Yu, Q.; Mayo, M. S. 2015. An application in identifying high-risk populations in alternative tobacco product use utilizing logistic regression and CART: a heuristic comparison, BMC Public Health 15: 341. https://doi.org/10.1186/s12889-015-1582-Z

Li, J.; Zhou, J.; Hu, Z. 2009. Safety analysis of overloaded truck for transportation, in R. Liu, J. Zhang, C. Gua (Eds.). Logistics: the Emerging Frontiers of Transportation and Development in China, 4067-4073. https://doi.org/10.1061/40996(330)595

Li, Z.; Wang, W.; Chen, R.; Liu, P. 2014. Conditional inference tree-based analysis of hazardous traffic conditions for rearend and sideswipe collisions with implications for control strategies on freeways, IET Intelligent Transport Systems 8(6): 509-518. https://doi.org/10.1049/iet-its.2012.0203

Liu, P.; Mu, D.; Gong, D. 2017. Eliminating overload trucking via a modal shift to achieve intercity freight sustainability: a system dynamics approach, Sustainability 9(3): 398. https://doi.org/10.3390/su9030398

Mahmoudabadi, A.; Abolghasem, A. 2013. Application of chaos theory in trucks' overloading enforcement, Journal of Engineering 2013: 245293. https://doi.org/10.1155/2013/245293

Mannering, F. L.; Bhat, C. R. 2014. Analytic methods in accident research: methodological frontier and future directions, Analytic Methods in Accident Research 1: 1-22. https://doi.org/10.1016/j.amar.2013.09.001

McDonnell, K.; Devlin, G.; Lyons, J.; Russell, F.; Mortimer, D. 2008. Assessment of GPS tracking devices and associated software suitable for real time monitoring of timber haulage trucks, in COFORD Annual Report 2008. National COuncil for FOrest Research and Development (COFORD), Dublin, Ireland. 53-54. 
Menard, S. 2001. Applied Logistic Regression Analysis. SAGE Publications. $128 \mathrm{p}$.

Moreno-Quintero, E.; Fowkes, T.; Watling, D. 2013. Modelling planner-carrier interactions in road freight transport: Optimisation of road maintenance costs via overloading control, Transportation Research Part E: Logistics and Transportation Review 50: 68-83. https://doi.org/10.1016/j.tre.2012.11.001

MoT PRoC. 2018. Statistic Bulletin of Development of Transportation Industry in 2017. Ministry of Transport of People's Republic of China (MoT PRoC). Available from Internet: http://www.mot.gov.cn (in Chinese).

MoT PRoC. 2016. 2016. Regulations on Highway Management for Oversized Transport Vehicles. Ministry of Transport of People's Republic of China (MoT PRoC). Available from Internet: http://www.mot.gov.cn (in Chinese).

Mujalli, R. O.; De Oña, J. 2013. Injury severity models for motor vehicle accidents: a review, Proceedings of the Institution of Civil Engineers - Transport 166(5): 255-270. https://doi.org/10.1680/tran.11.00026

Nandi, A.; Shakoor, A. 2010. A GIS-based landslide susceptibility evaluation using bivariate and multivariate statistical analyses, Engineering Geology 110(1-2): 11-20.

https://doi.org/10.1016/j.enggeo.2009.10.001

Nesa, N.; Ghosh, T.; Banerjee, I. 2018. iGRM: improved grey relational model and its ensembles for occupancy sensing in internet of things applications, ACM Transactions on Knowledge Discovery from Data 12(4): 47.

https://doi.org/10.1145/3186268

Nishida, N.; Tanaka, M.; Hayashi, N.; Nagata, H.; Takeshita, T.; Nakayama, K.; Morimoto, K.; Shizukuishi, S. 2005. Determination of smoking and obesity as periodontitis risks using the classification and regression tree method, Journal of Periodontology 76(6): 923-928.

https://doi.org/10.1902/jop.2005.76.6.923

Pais, J. C.; Amorim, S. I. R.; Minhoto, M. J. C. 2013. Impact of traffic overload on road pavement performance, Journal of Transportation Engineering 139(9): 873-879.

https://doi.org/10.1061/(ASCE)TE.1943-5436.0000571

Pillay, K.; Bosman, J. 2001. Heavy vehicle overload in the city of Tshwane, in 20th Annual South African Transport Conference "Meeting the Transport Challenges in Southern Africa", 16-20 July 2001, South Africa, 1-9. Available from Internet: https://repository.up.ac.za/bitstream/handle/2263/7924/1c5. pdf

Ramos, H. M.; Ollero, J.; Suárez-Llorens, A. 2017. A new explanatory index for evaluating the binary logistic regression based on the sensitivity of the estimated model, Statistics \& Probability Letters 120: 135-140.

https://doi.org/10.1016/j.spl.2016.08.022

Rys, D.; Judycki, J.; Jaskula, P. 2016. Analysis of effect of overloaded vehicles on fatigue life of flexible pavements based on weigh in motion (WIM) data, International Journal of Pavement Engineering 17(8): 716-726.

https://doi.org/10.1080/10298436.2015.1019493

Stanfill, C.; Waltz, D. 1986. Toward memory-based reasoning, Communications of the ACM 29(12): 1213-1228.

https://doi.org/10.1145/7902.7906

Titi, H. H.; Coley, N. J.; Latifi, V. 2018. Evaluation of pavement performance due to overload single-trip permit truck traffic in Wisconsin, Advances in Civil Engineering 2018: 1070653. https://doi.org/10.1155/2018/1070653

Torres Martínez, A. J.; Oliete Josa, S.; Magrinyà, F.; Gauthier, J.-M. 2018. Cost-effectiveness of enforcing axle-load regulations: the Douala-N'Djamena corridor in Sub-Saharan Africa, Transportation Research Part A: Policy and Practice 107: 216-228. https://doi.org/10.1016/j.tra.2017.11.016
Trzciński, G.; Moskalik, T.; Wojtan, R. 2018. Total weight and axle loads of truck units in the transport of timber depending on the timber cargo, Forests 9(4): 164.

https://doi.org/10.3390/f9040164

Trzciński, G.; Moskalik, T.; Wojtan, R.; Tymendorf, Ł. 2017. Zmienność ładunków i masy całkowitej zestawów wywozowych przy transporcie drewna, Sylwan 161(12): 1026-1034. (in Polish). https://doi.org/10.26202/sylwan.2017090

Van Loo, H.; Henny, R. 2005. REMOVE: Requirements for enforcement of overloaded vehicles in Europe, in Proceedings of International Conference on Weigh-in-Motion, 20-23 February 2005, Taipei, Taiwan, 1-9.

Wang, L.; Li, Q.; Yu, Y.; Liu, J. 2018. Region compatibility based stability assessment for decision trees, Expert Systems with Applications 105: 112-128.

https://doi.org/10.1016/j.eswa.2018.03.036

Wang, Y.; Priestley, J. L. 2017. Binary classification on past due of service accounts using logistic regression and decision tree, in Grey Literature from PhD Candidates. Paper No 4. Kennesaw State University, US. Available from Internet: https://digitalcommons.kennesaw.edu/dataphdgreylit/4/

Wu, D.; Jian, M.; Wei, F. 2012. Research on the highway freight overload supervision based on game theory, in ICLEM 2012: Logistics for Sustained Economic Development - Technology and Management for Efficiency, 8-10 October 2012, Chengdu, China, 681-686. https://doi.org/10.1061/9780784412602.0106

Xu, C.; Wang, W.; Liu, P.; Zhang, F. 2015. Development of a realtime crash risk prediction model incorporating the various crash mechanisms across different traffic states, Traffic Injury Prevention 16(1): 28-35.

https://doi.org/10.1080/15389588.2014.909036

Yassenn, O. M.; Hafez, M. A.; Endut, I. R.; Bin Baharom, I. B.; Ab Wahab, M. Y. 2011. Overloading at the northern part of the Malaysian expressway, in 2011 IEEE Colloquium on $\mathrm{Hu}$ manities, Science and Engineering, 5-6 December 2011, Penang, Malaysia, 76-81. https://doi.org/10.1109/CHUSER.2011.6163839

You, J.; Wang, J.; Fang, S.; Guo, J. 2017. An optimized real-time crash prediction model on freeway with over-sampling techniques based on support vector machine, Journal of Intelligent \& Fuzzy Systems 33(1): 555-562.

https://doi.org/10.3233/JIFS-162155

Zhang, H.; Lu, Y.; Shi, F.; Zhu, D. 2012a. Overloaded vehicle choice behavior analysis based on nested logit model, Journal of Transportation Systems Engineering and Information Technology 12(6): 113-118.

https://doi.org/10.1016/S1570-6672(11)60238-9

Zhang, W.; Zhang, Y.-M.; Wei, L.; Duan, X.; Chen, J. H. 2012 b. Influence of vehicle overloading on service life of highway, Journal of Traffic and Transportation Engineering 12(6): 8288. (in Chinese).

Zhao, Y.; Tan, Y.; Zhou, C. 2012. Determination of axle load spectra based on percentage of overloaded trucks for mechanistic-empirical pavement design, Road Materials and Pavement Design 13(4): 850-863.

https://doi.org/10.1080/14680629.2012.735796

Zhou, L. J. 2014. Economic analysis and governance countermeasure of overload and out-of-gauge on the highway, Advanced Materials Research 989-994: 5124-5127. https://doi.org/10.4028/www.scientific.net/AMR.989-994. 5124

Zuo, W.; Yuan, H.; Shang, Y.; Liu, Y.; Chen, T. 2016. Calculation of a health index of oil-paper transformers insulation with binary logistic regression, Mathematical Problems in Engineering 2016: 6069784. https://doi.org/10.1155/2016/6069784 